\title{
FAUNA, POPULATION AND ECOLOGY OF BIRDS IN TOWNS OF KYZYLKUM REGION
}

\section{National University of Uzbekistan named after Mirzo Ulugbek Doctor of biological sciences Kholboev F.R.}

Key words: Kyzyl-Kum, avian fauna, species composition and numbers of birds, urbanization, landscape, ecology, station, adaptation, avian fauna formation, nesting and wintering of birds, protection of birds.

\section{Abstract}

Recently, "urban ornithology" has become one of the priority and independent areas of modern science. In the second half of the 20th century, a lot of work was done in large cities of Europe, and ornithological research in the cities of Central Asia was insufficiently carried out, and this applies to the avifauna of cities in Uzbekistan.

Analyzes of recent studies show that the expansion of borders and a strong change in the architecture of cities in Uzbekistan has led to a change in the avifauna of urban ecosystems. These changes are observed in species diversity, population composition and ecology of birds. As a result, some species of birds disappeared from the territory of cities, and some, on the contrary, penetrated into the urban environment and the number of some species decreased greatly, while the number of others increased greatly. The study of these transformation processes is of theoretical and practical importance and is relevant for determining the further direction of the formation of avifauna and solving practical issues related to the protection and regulation of the number of some species and especially to optimize the relationship between people and birds.

The ornithology of the cities located in the Kyzylkum region of the Republic of Uzbekistan has not been studied before our study. We have 
studied the ornithology of the cities of Bukhara, Navoi, Zarafshan and Uchkuduk, which differ in ecological conditions. A comparative study of the avifauna of older (Bukhara, Navoi) and new cities (Zarafshan, Uchkuduk) located in different parts of the desert, in the long term, makes it possible to provide ecological forecasting of the formation and development of avifauna.

The purpose of this study is to determine the current state and patterns of formation of the avifauna of the cities of the Kyzylkum region. The solution of the following tasks was envisaged:

Identification of environmental factors that determine the features of the habitat of birds in cities and the patterns of formation and dynamics of urban avifauna; study of the species composition and nature of the stay of birds; to analyze the fauna and bird population of the cities of the Kyzylkum region; to study long-term and seasonal dynamics of the number of birds; assess the adaptation of birds to urban conditions; to reveal the ways of avifauna formation in the cities of the region; determine the relationship of birds to urbanized areas and natural landscapes in different phenological periods; determine the importance of birds in urban environments; to develop a scientific basis for the protection and control of numbers.

Material and research methods. The work used zoological and ecological research methods. To account for the number of birds, generally accepted methods were used (Kuzyakin et al., 1958; Dobrokhotov and Ravkin, 1961; Lugovoi, Maykhruk, 1974; Bozhko, 1976; Pesenko, 1982; Chelintsev, 1985). Birds were counted in all seasons of the year and in all types of stations in the city on permanent fixed routes. The counts were carried out by the linear transect method, 5-minute counts and at stationary counting sites. Materials on the ecology of birds during the period of breeding, wintering, and other life cycles were collected according to wellknown methods (Malchevsky, 1950, 1959; Novikov, 1953). The analysis of bird nesting features is based on the results of a survey of 857 nests, 374 eggs 
and 109 chicks, a total of 16 bird species. Phenological and diurnal relationships of avifauna have been studied in cities and their surroundings (agrocenoses, settlements, natural landscapes). The significance of birds in the conditions of the city and adjacent territories was studied in places of feeding, resting, spending the night and nesting.

Experiments with optical and acoustic repellents were carried out to study the problems associated with the regulation of the number of certain bird species (Donika, 1963; Lanovenko and Filatov, 1978; Ilyichev, 1984; Estafiev, 1984; Dzhabbarov, 1998, etc.). The classification of urban biotopes is given according to V.M. Brave (1986), with adaptation to the local conditions of the region.

The material for this work was the results of field studies carried out from 2001-2017. in the cities of the Kyzylkum region and their environs. The main work on the study of the species composition, quantitative counts of birds and the ecological features of the avifauna were carried out in the 7 types of stations identified by the author in these cities.

\section{Introduction}

In the development of ornithological research in cultural landscapes, including cities, the scientific activity of N.A. Gladkov and A.K. Rustamov $(1958,1965,1966)$.

Some research materials carried out in different cities of Uzbekistan are reflected in the works of Sataev (1937), Sharipov (1970), Mambetzhumaev and Ametov (1974), Mecklenburtsev (1982), Kashkarov and Ayupov (1987), Ayupov (1991), Lanovenko (1993) and etc.

In the studied cities (Bukhara, Navoi, Zarafshan and Uchkuduk) of the Kyzylkum region, 137 bird species belonging to 17 orders were recorded. By the nature of their stay, they can be divided into 5 groups (table). 
Table

The modern composition of the avifauna of the cities of the Kyzylkum region and the distribution of groups by the nature of their stay

\begin{tabular}{|l|l|l|l|l|l|l|l|l|}
\hline \multirow{2}{*}{$N$} & Goups & \multicolumn{2}{l}{ Number of species } & \multicolumn{3}{l}{ Nature of stay } \\
\cline { 3 - 11 } & & Abc. & $\%$ & S & N & M & W & IO \\
\hline 1 & Podicipediformes & 1 & 0,7 & - & - & - & 1 & - \\
\hline 2 & Pelicaniformes & 1 & 0,7 & - & - & - & 1 & - \\
\hline 3 & Ciconiiformes & 5 & 3,6 & - & 1 & 3 & 1 & - \\
\hline 4 & Anseriformes & 3 & 2,2 & - & - & 2 & 1 & - \\
\hline 5 & Falconiformes & 9 & 6,6 & - & 3 & 2 & 4 & - \\
\hline 6 & Galliformes & 2 & 1,4 & 1 & - & 1 & - & - \\
\hline 7 & Gruiformes & 2 & 1,4 & 1 & - & 1 & - & - \\
\hline 8 & Charadriiformes & 21 & 15,3 & - & - & 19 & 2 & - \\
\hline 9 & Columbiformes & 6 & 4,4 & 3 & 1 & 2 & - & - \\
\hline 10 & Cuculiformes & 1 & 0,7 & - & 1 & - & - & - \\
\hline 11 & Strigiformes & 5 & 3,6 & 1 & 1 & 1 & 2 & - \\
\hline 12 & Caprimulgiformes & 1 & 0,7 & - & - & 1 & - & - \\
\hline 13 & Apodiformes & 1 & 0,7 & - & 1 & - & - & - \\
\hline 14 & Coraciiformes & 4 & 2,9 & 1 & - & 3 & - & - \\
\hline 15 & Upupiformes & 1 & 0,7 & - & 1 & - & - & - \\
\hline 16 & Piciformes & 1 & 0,7 & & - & 1 & - & - \\
\hline 17 & Passeriformes & 73 & 53,3 & 9 & 10 & 27 & 16 & 11 \\
\hline Итого & 137 & 100 & 16 & 19 & 63 & 28 & 11 \\
\hline
\end{tabular}

Note: S - sedentary, N - nesting, M - migratory, W - wintering and IO - irregularly occurring.

In the bird population, the participation of sedentary species is $11.7 \%$, nesting - $13.9 \%$, migratory - $46.0 \%$, wintering - $20.4 \%$ and irregularly occurring "visitors"- $8.0 \%$. 
In the studied cities and the surrounding cultural and natural landscapes, the species composition of birds decreases in the following direction: natural landscapes $\rightarrow$ agrocenoses with rural-type settlements $\rightarrow$ cities, and the bird population density decreases in the direction from the city to the desert: city $\rightarrow$ agrocenoses with settlements $\rightarrow$ natural landscapes. If we extrapolate the number of species per unit area, we get a completely different picture: agrocenoses with rural-type settlements $\rightarrow$ cities $\rightarrow$ natural landscapes.

In urban ecosystems, the quantity and quality of habitats gives rise to a corresponding number of ecological niches. Therefore, the species composition of birds in the urban landscape is richer than in the natural landscape with the same area.

In the cities we studied, the number of species is not the same: in the city of Bukhara, 137 species were registered, in Navoi-92, in Zarafshan-49 and in Uchkuduk-28 species of birds. This trend is based on geographic location, age, and ecological characteristics of cities and their surrounding landscapes.

The various stations that make up the city are unique in structure and complexity. This influences the nature of the formation of the population and the distribution of birds in each habitat. The species composition of birds living in different parts of the city is determined, first of all, by the characteristics of the station.

In the studied cities, the number and quality of stations, as well as the species diversity of birds, is not the same: in Bukhara, 7 types of stations can be distinguished, in Navoi-5, in Zarafshan-4, in Uchkuduk-3. In terms of the diversity of species, for example, in the city of Bukhara, the green areas have a high indicator (89 species), and the ruderal areas, on the contrary (20 species). This tendency was observed in other cities of the Kyzylkum region (Fig. 1).

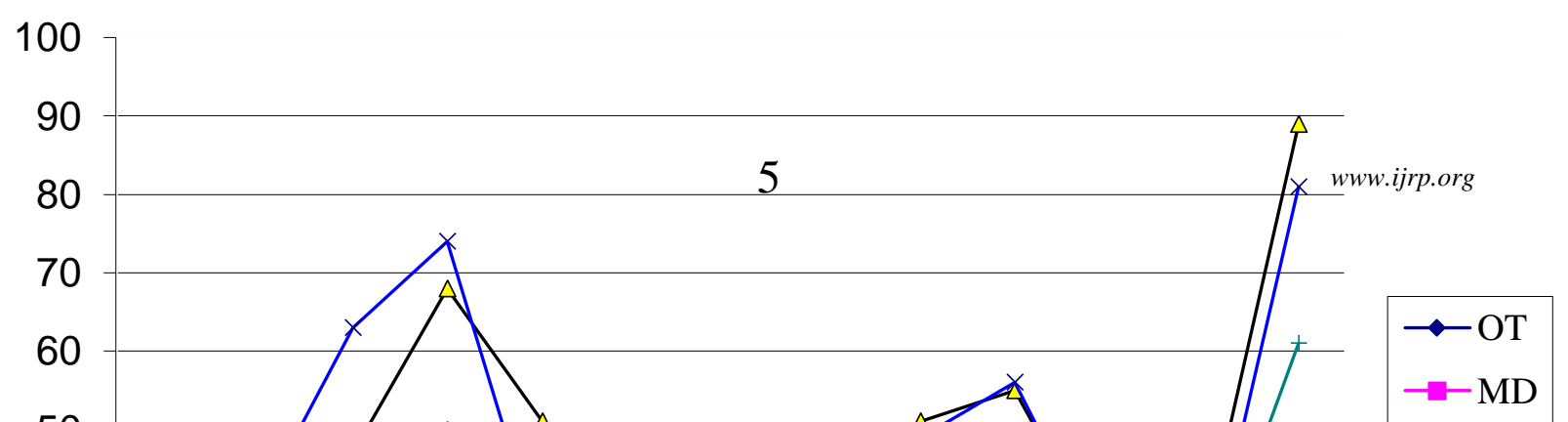


Figure: 1. The number of species and their annual dynamics for the main stations of the city of Bukhara

Note: OT - old town, MD - micro districts, GA - green areas, R - reservoirs, RA ruderal areas, IC - industrial centers, C - cemeteries.

In the studied cities, in late autumn (November), winter and early spring (March, April), the number of birds increases, in hot seasons it greatly decreases. The maximum number is observed in January, the minimum in July and August. Moreover, the density of birds per unit area of a certain station, in most cases, does not depend on the number of species.

In the green areas (parks, squares) of the city, the average annual number of birds per 10 hectares. the area ranges from 315 (Uchkuduk) to 894 individuals (Bukhara) (Fig. 2). Especially in winter, this station is used for the night by numerous species (Acridotheres tristis, Pica pica, Corvus 
frugilegus, Corvus cornix), so the population density increases greatly.

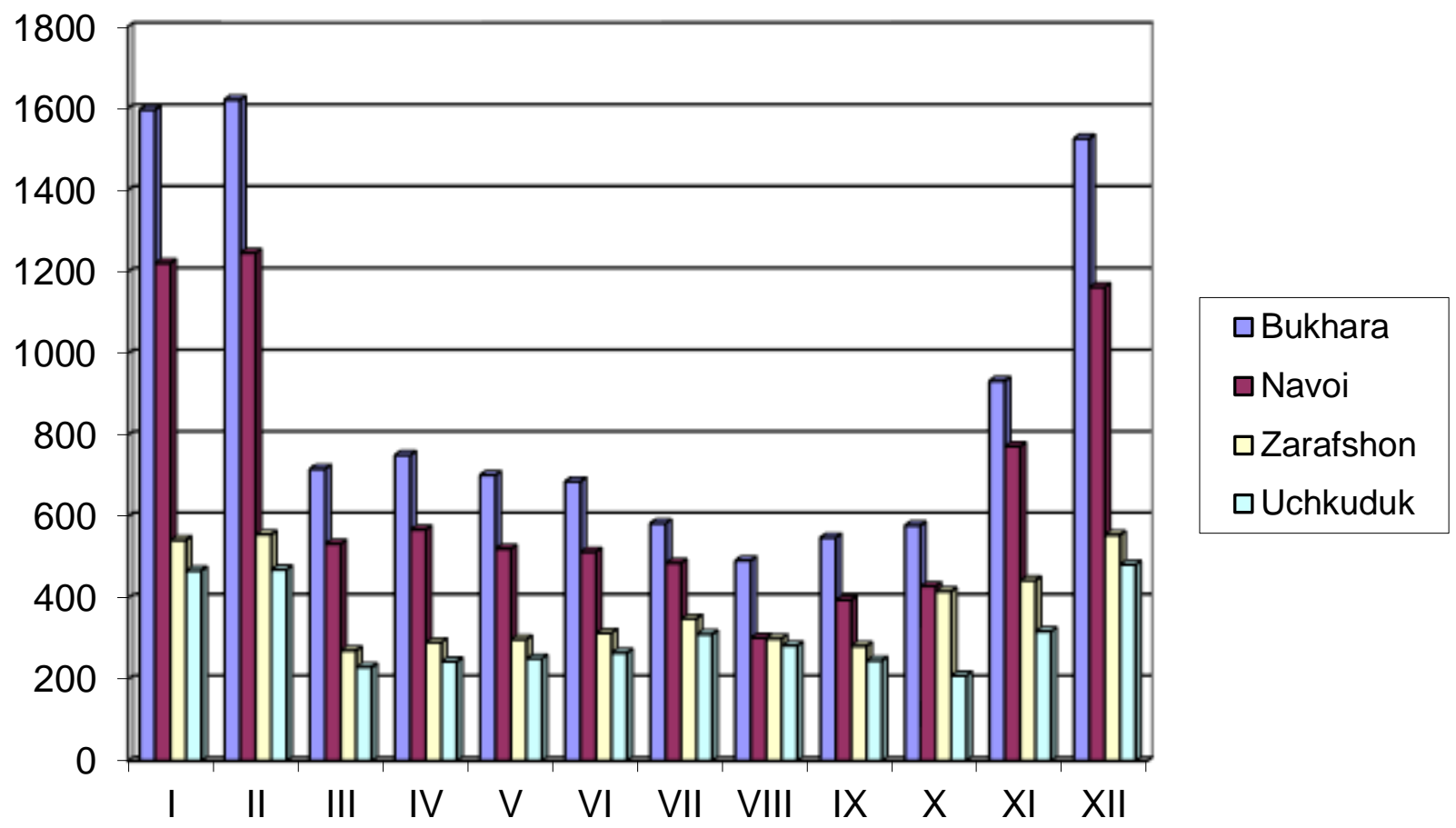

Figure: 2. Average annual dynamics of the number of birds in green areas of the cities of the Kyzyl-Kum region (2001-2017).

Some specific features of the ecology of the urban population of species (feeding, nesting, wintering, behavior), which differ from those of natural ones, have been determined. For example, an expansion of the spectrum of food components, atypical nesting, an increase or change in daily activity. Due to these adaptive changes, the population becomes a typical representative of urban landscapes.

In the cities of the Kyzylkum region, we noted nesting of 35 bird species (16 sedentary and 19 migratory-nesting). Among them, Columba livia, Streptopelia senegalensis, Acridotheres tristis, Pica pica, Corvus frugilegus and Passer montanus are very numerous sedentary species and these species form the basis of the avifauna population of the cities of the region in all seasons of the year. However, in the studied cities, the number of Otus brucei, Athene noctua, Upupa epops, Hirundo rustica decreased markedly. In Bukhara, Dendrocopos leucopterus (1970) and Ciconia ciconia 
(1981) stopped nesting, and starting in 1980, Hirundo daurica began to nest, Streptopelia decaocto from 1988, Gallinula chloropus from 1998 and Nycticorax nycticora from 2008.

As a result, increased competition for nesting sites, negative anthropogenic impact and predation of domestic cats and dogs negatively affect the breeding of nesting species and the success of these breeding of the studied species (16 species) averages $47.3 \%$, which is slightly lower than in the urban environment this region.

In the winter season, 44 species of birds were recorded in the cities of this region (wintering-28 species and sedentary-16). In the population of wintering birds, more than $93 \%$ are sedentary species, and during this period the population density reaches its maximum.

Spatio-temporal distribution, species diversity, bird abundance and its dynamics depend on the specific features of the stations. These indicators, as a kind of bioindicators, determine the ecological state of the city. Comparative analysis confirms that in urban areas with a decrease in the number of stations, the abundance of species and the density of the bird population decrease.

Various communication systems, settlements, agrocenoses and natural landscapes are important in the formation of the city's avifauna, as well as as a kind of "bridges" support the relationship between the city's bird communities.

Ornithocomplexes of the cities of Bukhara and Navoi in the process of formation have historically been associated with slightly altered landscapes through modified landscapes (Fig. 3). Since historical times, there have been active phenological and trophic relationships between the bird communities of these cities. In contrast to these cities, at present, certain modified landscapes have not been formed around Zarafshan and Uchkuduk. In this regard, in these cities, the species composition and population density of birds 
are more stable and have low rates. The latter can only be updated after the formation of modified landscapes around these cities.

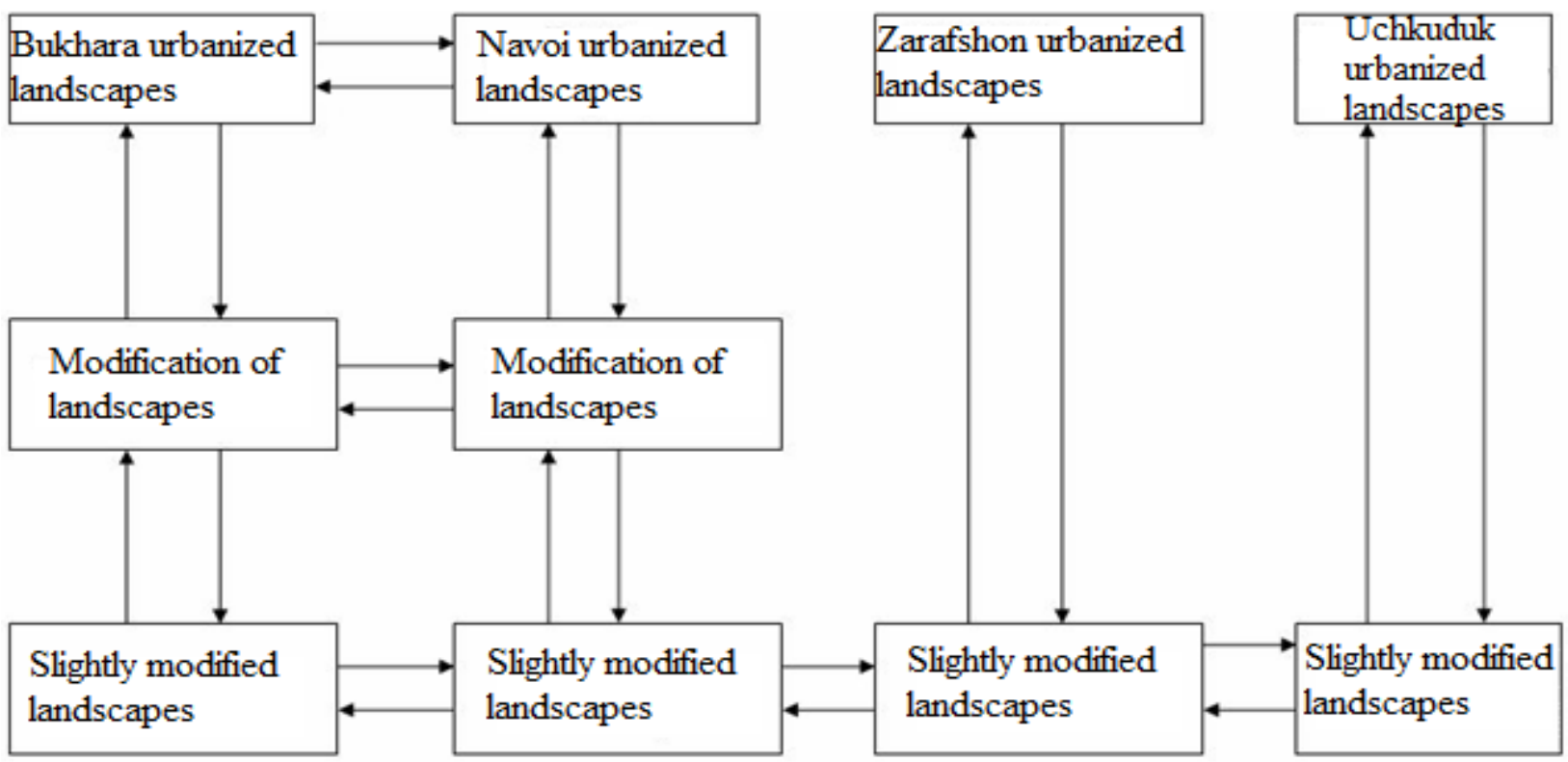

Figure: 3. The relationship of the avifauna of urbanized, modified and slightly altered landscapes in the process of their formation.

Our analyzes show that the formation of the avifauna of a certain city, although they are located in the same region, proceeds at different rates and reaches different degrees of completion. This pattern is associated with the relationship between landscapes and is typical in regions where natural conditions are extreme and the landscape is highly susceptible to anthropogenic transformation.

\section{Conclusions}

In recent years, large-scale development and degradation of the natural landscapes of the Kyzyl Kum desert has led to an increase in the transformation of the region's avifauna. In such situations, urban ecosystems 
as a new habitat for some urbanophilic species are important in conserving bird diversity. The study of the avifauna of cities located in different parts of the desert provides an opportunity for ecological forecasting of the formation and development of ornithocomplexes and solving some socio-economic issues.

The multitude of different stations determines the mosaic nature of urban ecosystems and the corresponding number of ecological niches, and in this regard, the species composition of birds of a certain city is richer than in natural landscapes of similar sizes.

The study of the bird population at the stations of the city is effective in the development of protection measures, behavior management, purposeful formation, as well as in assessing and forecasting the development of avifauna in the future.

The formation, development and evolution of the avifauna of the cities of the Kyzylkum region are closely related to the geographical location and ecological conditions of the city, as well as to the surrounding natural and cultural landscapes of the city.

The adaptation of birds to urban conditions is important for determining the direction of evolutionary processes occurring in the ecology of birds, and serve as a criterion for ensuring their existence.

The revealed patterns of avifauna formation can be used in the development of the theory of adaptation of birds to urban landscapes and in the optimization of biotechnical measures to preserve bird diversity. They must certainly be taken into account in urban planning, air services, sanitary and epidemiological surveillance and nature protection.

\section{Literature}


1. Kholboyev F.R. Ways of adaptation of birds to the conditions of the cities of the Kyzylkum region // Reports of the Academy of Sciences of the Republic of Uzbekistan. - Tashkent, 2005. - No. 4. - pp. 86-88.

2. Kholboyev F.R. Ecological features of the avifauna of the cities of Zarafshan and Uchkuduk // International scientific research. - Moscow, 2010. - No. 1-2. - P.118-120.

3. Kholboyev F.R. Some features of the transformation of the avifauna of the Kyzylkum desert // Bulletin of NUUz. - Tashkent, 2010. - №3 / 1. - S. 190-191.

4. Kholboyev F.R. The practical importance of birds and control of their numbers in the urban environment of Kyzylkum // Reports of the Academy of Sciences of the Republic of Uzbekistan. - Tashkent, 2010. - No. 6. - S. 6768.

5. Kholboev F.R. Seasonal dynamics of wintering and nesting avian species in towns of Kyzylkum region // International scientific researches. Moscow, 2011.- No. 1-2. - P. 112-114.

6. Kholboyev F.R. Ways of adaptation of birds to the conditions of cities of the Kyzylkum region // The role of ecological space in ensuring the functioning of living systems: Mater. first between. scientific - practical conf. - Yelets, 2005. - pp. 38-40.

7. Kholboyev F.R. Some data on the avifauna of the cities of the Kyzylkum region (on the example of Uchkuduk) // Biology - science of the XXI century: 10th Pushchino school-conf. young scientists, dedicated to the 50th anniversary of the Pushchino Scientific Center of the Russian Academy of Sciences. - Pushchino, 2006 .-- P. 326.

8. Kholboyev F.R. Comparative characteristics of the bird fauna of the cities of the Kyzyl Kum desert // Biology is a science of the XXI century: 12th Pushchino school-conference of young scientists. - Pushchino, 2008 .-S. 323. 
9. Holboev F.R. The relationship between the bird fauna of urbanized areas and natural landscapes in different phenological periods // Biology Science of the XXI century. 12th Pushchino School-Conference of Young Scientists. - Pushchino, 2008 .-- S. 324.

10. Kholboyev F.R. Ecological analysis of the avifauna of the cities of the Kyzylkum region // Modern problems of ornithology of Siberia and Central Asia: IV Inter. ornith. conf. - Ulan-Ude, 2009. - pp. 295-297. 